\title{
LA INDUSTRIALIZACIÓN POR SUSTITUCIÓN DE IMPORTACIONES (ISI): USOS Y SENTIDOS DE UNA EXPRESIÓN POLISÉMICA
}

\author{
Import substitution industrialization (ISI): uses and senses of a polysemic expression
}

\author{
Federico Hernán Reche* \\ https://orcid.org/0000-0003-3048-7780
}

\section{Resumen}

Frente a la pregunta ¿qué es la ISI? la diversidad de respuestas posibles no refleja sólo disensos historiográficos o de la teoría económica. La expresión industrialización por sustitución de importaciones - ISI - posee un marcado carácter polisémico que ha sido descuidado por las investigaciones sociales; y que, no advertido correctamente, puede haber obstaculizado y confundido discusiones relevantes en el campo de la historia económica argentina. En este artículo se presenta, a partir de una revisión de la literatura, la multiplicidad de usos y sentidos con que es utilizada en la historiografía argentina la expresión Industrialización por sustitución de importaciones. De acuerdo con nuestro argumento principal esta puede referir, en efecto, a tres fenómenos diferentes: una práctica económica, un período histórico y una estrategia de desarrollo.

$$
\begin{gathered}
<\text { Industrialización por Sustitución de Importaciones }><\text { Historiografía económica }> \\
<\text { Industrialización argentina }><\text { CEPAL }>
\end{gathered}
$$

\begin{abstract}
What is ISI? The diversity of possible answers does not only reflect historiographic dissent or relative to the economic theory. The expression import substitution industrialization - ISI - has a markedly polysemic character that has been ignored by social research; and that, not properly warned, may have hindered and confused relevant discussions in the field of Argentine economic history. This paper presents, from a review of the literature, the multiplicity of uses and meanings with which the expression Industrialization by import substitution is used in Argentine historiography. According to our main argument ISI can refer, in effect, to three different phenomena: an economic practice, a historical period and a development strategy.
\end{abstract}

$<$ Import substitution industrialization $><$ Economic History $><$ Industrialization in Argentina $><$ CEPAL $>$

Recibido en 25/01/2019

Aceptado en 15/05/2019

\footnotetext{
* Centro de Investigación María Saleme Burnichon - Facultad de Filosofía y Humanidades, Universidad Nacional de Córdoba. Becario Doctoral del Consejo Nacional de Investigaciones Científicas y Técnicas (CONICET), Argentina, rechefederico@gmail.com
} 
Reche. La Industrialización por Sustitución de Importaciones (ISI): usos y sentidos de una expresión polisémica

\section{Presentación}

La expresión industrialización por sustitución de importaciones - ISI- posee un carácter polisémico que ha sido descuidado por las investigaciones sociales. Aun cuando siempre hace referencia a cuestiones estrechamente vinculadas, éstas corresponden a planos diferentes de la realidad o a procesos históricos de distinto alcance. Desde nuestro punto de vista, este carácter polisémico, no advertido correctamente, puede haber obstaculizado y confundido discusiones relevantes en el campo de la historia económica argentina.

En efecto, lo expuesto en este trabajo resulta de una necesaria aclaración conceptual que permita abordar debates historiográficos referidos al desempeño de la economía nacional y la viabilidad de la industrialización en los países dependientes. Reconstruir y analizar disputas interpretativas sobre el final de la ISI, su supuesto agotamiento -datado en diferentes momentos, según las perspectivas- o interrupción, producto de la deliberada política económica de la última dictadura cívico militar argentina, implica someter a crítica las producciones de economistas e historiadores a fin de advertir los supuestos teórico-políticos y las significaciones que en cada época han adquirido sus afirmaciones. Sin embargo, esta tarea resulta imposible sin un proceso previo: aclarar(nos) a qué refiere la expresión "industrialización por sustitución de importaciones". En verdad, resulta probable que autores como Aldo Ferrer o Marcelo Diamand hayan referido al agotamiento de la industrialización sustitutiva con un significado algo diferente del sostenido por Portantiero, Braun o Halperín Donghi. Incluso, las diferencias son tan claras entre los últimos, como entre las producciones de algunos de ellos en diferentes contextos político-intelectuales; por ejemplo, las afirmaciones de Portantiero de los años 70 y los 80 .

Comprender estas polémicas y las construcciones intelectuales al respecto, que han sustentado disputas interpretativas, políticas y económicas en el siglo XX argentino, requiere de una mirada atenta sobre aquello que se nombra en el objeto de la polémica. Esto debido a que, como pretendemos justificar en este trabajo, la expresión "ISI" - y/o sus variaciones- no nombra siempre y en todos los casos al mismo fenómeno.

En verdad, la expresión ISI surgió en la segunda mitad de la década del sesenta, al mismo tiempo que la idea de su agotamiento, en el marco de los esfuerzos por caracterizar el desarrollo típico de América Latina de aquellos años. Los debates económicos producidos en esta coyuntura estuvieron orientados a comprender los fenómenos estructurales que promovían y explicaban la crisis que las economías latinoamericanas vivían, en relación con el proceso de desarrollo industrial y la restricción externa. Aunque inicialmente la expresión resultó una forma de nombrar el período de desarrollo que comenzó circa 1930 en América Latina, según intentaremos demostrar en el presente trabajo, es posible identificar la existencia de al menos tres sentidos o usos habituales. El primero de ellos refiere a una práctica económicoproductiva; el segundo, a un período histórico de la economía nacional; y el tercero, a una programática económico-política como estrategia de desarrollo. 
Así, abordaremos la industrialización sustitutiva con el objetivo de precisar conceptual e históricamente los diversos significados otorgados por las investigaciones sociales. Este esfuerzo no se orienta a optar por una definición o acepción específica, sino que, por el contrario, intenta dar cuenta de la multiplicidad de significados posibles con los que se presenta, en ocasiones, incluso en los mismos autores.

\section{La industrialización sustitutiva de importaciones como práctica económica}

Según adelantamos, la expresión “industrialización por sustitución de importaciones" designa, en primer lugar, una práctica económica. Vinculada al ámbito de la producción, describe el proceso productivo por medio del cual se desarrolla la elaboración de bienes industriales manufacturados, antes importados desde los países centrales industrializados. Este fenómeno tiene lugar cuando, en países que no participaron del proceso original de surgimiento del capitalismo industrial ${ }^{1}$, se comienzan a producir bienes propiamente industriales a fin de reemplazar productos antes comprados en el exterior y que son consumidos en el marco de la propia economía nacional.

Antes de avanzar, es importante marcar que nos referimos a una actividad históricamente situada. En ocasiones, el término industria puede encontrarse utilizado para referir genéricamente a la producción de bienes en las que el hombre hace uso de herramientas o máquinas, incluso cuando se describen actividades de sociedades en las que no predominan relaciones capitalistas de producción. Así, aparecen referencias a la "industria antigua" o la "industria precolombina" o la "industria neolítica" 2 . Estas otras acepciones del término resultan extrañas al fenómeno económico político al que se hace referencia en el marco de nuestra reflexión y que se presenta exclusivamente como característico de las sociedades capitalistas contemporáneas. En estas sociedades, la industrialización ${ }^{3}$ se presentó como uno de los rasgos distintivos del desarrollo

1 Si bien el desarrollo de la industria capitalista ha encontrado su centro en diversas regiones del mundo en distintas etapas históricas, en raras ocasiones se ha desarrollado de manera original por medio de procesos de acumulación originaria que impulsaron de manera primigenia la formación de relaciones capitalistas de producción, de acuerdo con el planteo de Marx ([1867] 2000). En las siguientes páginas nos referimos brevemente a la Revolución Industrial Inglesa y posteriores experiencias de industrialización tal como han sido consideradas en los clásicos planteos sobre el desarrollo.

2 Sin necesidad de hacer referencia a cuestiones tan disímiles, en el clásico y pionero texto de Ingeniero Dorfman ([1942] 1970) aparece esta consideración laxa de industria, entendida como "toda actividad o labor productiva que transforma materias, que modifica sus propiedades de manera tal que las hace aptas para el consumo bajo una forma distinta a la que tenían antes de entrar en el proceso de elaboración" (p. 11). Esta acepción amplia de industria es la que exonera a los historiadores de la anacronía que supondría catalogar como industrias a las actividades artesanales y domésticas, tal como generalmente se hace. En los estudios de historia económica o general, dedicados tanto a la Antigüedad Tardía como a la Colonia Americana, aparecen referencias a la industria, aunque no sea esta la característica industria capitalista europea. Por ejemplo, en el clásico libro Mercaderes del Litoral, José Carlos Chiaramonte (1991), al explorar la economía y sociedad de la provincia de Corrientes en la primera mitad del siglo XIX, estructura su exposición dedicando capítulos particulares a los diferentes sectores productivos (III. Comercio, mercado y transportes; IV. La producción agropecuaria; V. Las industrias).

3 Sobre la noción de industrialización, véase Bagchi (1993). Esta apretada síntesis recorre los principales debates acerca de este fenómeno y ordena las referencias de la literatura más importante. Asimismo, 
Reche. La Industrialización por Sustitución de Importaciones (ISI): usos y sentidos de una expresión polisémica

capitalista y, al mismo tiempo, definitorio y concentrador del progreso tecnológico. El surgimiento histórico de la producción industrial capitalista tuvo lugar, como se sabe, con la denominada Revolución Industrial en Inglaterra a mediados del siglo XVIII. Ésta no solo transformó los procesos productivos y las características y el volumen de los bienes socialmente producidos, sino que alteró el conjunto de la vida social. Para Arnold Toynbee (1884), el inventor de la denominación Revolución Industrial, ella implicó, por su carácter total (Mokyr, 1987), al igual que otros pocos procesos sociales, un nuevo punto de partida para la historia de la humanidad. Según esta perspectiva, la Revolución Industrial fue algo más que industrial y constituyó, por el contrario, un decisivo impulso en la transformación del mundo conocido.

Al margen de los debates existentes sobre la periodización, que no resultan relevantes en nuestra exposición, es central destacar que la ubicación temporal del desarrollo del capitalismo industrial ${ }^{4}$ iniciado en Gran Bretaña en la segunda mitad del siglo XVIII y en Estados Unidos durante la primera mitad del siglo XIX, se presentará suficientemente consolidado en un conjunto de regiones desde el cual se desarrollará y expandirá desde mediados del siglo XIX: Gran Bretaña, los Países Bajos y Estados Unidos. Desde estos centros, posteriormente, todos los espacios y las regiones del mundo fueron incorporados al sistema capitalista por medio de su expansión e impulso ${ }^{5}$. En este marco, solo en escasas ocasiones el desarrollo de la industria local en otros países se dio de manera original o endógena. En algunos, una vez iniciadas las trasformaciones productivas impulsadas por el capitalismo, se desarrollaron complejos industriales novedosos sobre la base de un proceso de acumulación interno ${ }^{6}$, pero en la mayoría se experimentaron prácticas sustitutivas a medida que desarrollaban sus actividades industriales y sus mercados internos. Sobre la base de estos desarrollos sustitutivos, la industria se expandió, por ejemplo, en el Extremo Oriente o en el Cono Sur (Félix, 1987).

Aun así, es necesario distinguir esta forma de avance de la actividad industrial de aquellas en que las manufacturas se ven estimuladas por el desarrollo exportador de los países y/o por procesos de innovación técnica propia. En Argentina, la industrialización sustitutiva -en la que nos concentramos en estas líneas- se desarrolló aun durante el período de preeminencia del modelo agroexportador orientado al Atlántico y fundado en la relación de "complementariedad económica" con Gran Bretaña. Pero no todas las actividades y los establecimientos industriales que se desarrollaron en el período corresponden con una práctica sustitutiva. Al contrario, las principales actividades industriales de esta etapa fueron impulsadas por la actividad agropecuaria exportadora ${ }^{7}$.

sobre la distinción de la industrialización capitalista y aquella ocurrida en los países socialistas (URSS y otros del denominado "socialismo real"), puede verse Sweezy (1973).

${ }^{4}$ Respecto de la expansión de la industria en el siglo XIX, puede repasarse Hobsbawm (2007) -en particular, los capítulos 2 y 9-, Cipolla (1979) -volumen 3 y 4-, Wallerstein (1998) y Berg (1987).

5 Véase Wallerstein (1998).

${ }^{6}$ Los casos más relevantes son quizás Alemania y Japón. Puede consultarse la compilación a cargo de Rostow (1967), en la que se analiza una amplia variedad de experiencias de industrialización de diversos países. También, el pionero Gerschenkron (1973) sobre las experiencias de Europa continental. Para el caso de Japón, puede consultarse además Takahashi (1986).

7 Al respecto y para obtener una mirada más general sobre el conjunto del fenómeno en América Latina, 
Solo así resulta comprensible un planteo como el de Neffa (1998, p. 109), para quien en la etapa previa a los ' 30 se ubica la "primera fase del proceso de industrialización mediante sustitución de importaciones (ISI)". Pero la industria de estos años puede ser abordada y caracterizada desde un criterio de mercado y puede agruparse en dos grandes conjuntos. El primero, de las denominadas "agro-industrias" que, sobre la base de materias primas agropecuarias, desarrollaban bienes destinados a la exportación y sobre los que se evidenciaba una mayor presencia de capitales extranjeros. El otro, de las llamadas "industrias artificiales", destinadas al mercado interno. En estas,

[los] capitales eran mayoritariamente de origen nacional, transformaban materias primas producidas sobre todo en el país, pero utilizaban una alta proporción de maquinarias, equipos e insumos importados. Su dinamismo se modificaba en forma directamente proporcional a la amplitud y duración de las crisis y de la recesión de los países industrializados (...) estas restricciones significaban un estímulo a la producción nacional de bienes sustitutivos. (Neffa, 1998, p. 113)

De esta manera, en el período considerado, el impulso de las exportaciones fue el estímulo más importante de las actividades industriales con mayor relevancia y dinamismo. Por ello, el principal fenómeno expansivo se dio por medio de los grandes frigoríficos, los molinos harineros, los talleres de ferrocarriles, los ingenios azucareros y las plantas elaboradoras de tanino (Cf. Villanueva, 1972; Katz y Kosacoff, 1989). Sin embargo, en el marco del modelo económico prevalente desde fines del siglo XIX y comienzos del XX, que incorporó a la Argentina a la división internacional del trabajo (DIT) como país productor y exportador de bienes agropecuarios, se desarrolló una industria promovida y protegida por medidas tomadas como consecuencia de crisis internas o externas que sacudieron el comercio internacional ${ }^{8}$. Aunque, tal como ha señalado Chiaramonte (1986), los principios políticos e ideológicos de los sectores dominantes en Argentina no se apartaron de los postulados esenciales del liberalismo de la época, diversas crisis económicas de la segunda mitad del siglo XIX permitieron una mayor recepción de algunos reclamos que demandaban protección industrial (Odisio, 2014). Estos planteos a favor del desarrollo de manufacturas habrían surgido incluso en referentes de la Sociedad Rural Argentina (Cornblit, Gallo y O'Connell, 1962; Chiaramonte, 1986). La abundante bibliografía existente sobre esta etapa previa a la década del treinta ${ }^{9}$ no será abordada aquí, ya que sólo nos interesa advertir de qué

puede verse Lewis (1991).

8 Estas crisis empujaron a sucesivos cambios en las conceptualizaciones sobre la industria producto de desplazamientos "epocales" en los que resultan centrales tanto las innovaciones en los saberes y las ideas como las trasformaciones sociales y económicas que de manera interna y externa habilitaron, promovieron o volvieron ineludible la industrialización local.

9 Algunos de los principales trabajos que deberían revisarse sobre este período son Arceo (2003), Cortés Conde (1965, 1997), Díaz Alejandro (1975), Di Tella y Zymelman ([1961] 1967), Dorfman ([1942] 1970), Ferrer ([1973] 2000), Katz y Kosacoff (1989), Llach (1985), Peña (1986), Sábato (1988), Schvarzer (1996) y Villanueva (1972). 
Reche. La Industrialización por Sustitución de Importaciones (ISI): usos y sentidos de una expresión polisémica

manera la industrialización emprendida se produjo "bajo la presión de los hechos" y resultó en principio contraria a la proyección económica de los poderes del Estado. Durante los años del modelo agroexportador, estas industrias de carácter sustitutivo tuvieron escasa relevancia macroeconómica en la economía nacional, aunque esto cambiará fuertemente poco tiempo después.

Uno de los primeros ciclos de impulso a la sustitución de importaciones se originó específicamente en la ruptura del esquema de librecambio producida a partir de la crisis de 1890 y las medidas proteccionistas adoptadas posteriormente por el Estado ${ }^{10}$. Sin embargo, estas condiciones rápidamente se dejarán atrás y el siguiente momento de impulso a la industrialización se dará a partir de las restricciones al comercio internacional que introdujo, en los hechos, la Primera Guerra Mundial. Producto de estos estímulos, la producción industrial creció considerablemente y llegó a multiplicarse cuatro veces desde 1900 a 1930; de manera que el "proceso de industrialización orientado hacia la sustitución de importaciones se desarrolló, siguiendo su propia dinámica, sin que hubiera una política gubernamental deliberada dirigida al sector" (Neffa, 1998, p. 114). Sin embargo, en el periodo que va de la Gran Guerra a la Crisis del '30, las ideas, propuestas e interpretaciones sobre la industria se renovaron y reimpulsaron a partir de formulaciones de diversos dirigentes políticos, intelectuales y militares. Al respecto, se ha insistido en la importancia de la Revista de Economía Argentina y la figura de Alejandro Bunge en el abono a un campo de debates y polémicas más ricas y complejas a las existentes hasta ese momento (Rougier y Odisio, 2014). En efecto, el cambio en el clima de ideas a comienzo de siglo no puede ser soslayado al momento de comprender las polémicas de los inmediatos ' 30 y la aplicación de políticas que sin duda favorecieron el desarrollo de la industrialización argentina, aun en el marco del modelo de crecimiento guiado por las exportaciones primarias. A ese mismo clima de época favoreció la recepción de ciertas ideas sociales, filosóficas y económicas que ponían de relieve la "cuestión social" y la necesidad de la intervención del Estado en los procesos económicos y sociales (Lucchini, Blanco y Cerra, 2000; Rougier y Odisio, 2014 y Caravaca, 2011).

A esa larga etapa preparativa, en la que la industria se desarrollará, aunque lentamente por distintas vías, le sucederá una nueva ruptura del libre comercio, que fue también la más importante, debido a su profundo impacto en el conjunto del mundo capitalista. En nuestro país, la crisis de los ' 30 generó un grave problema de balanza de pagos bajo el cual se implantó el control de cambios y se restringieron las importaciones. A diferencia de las experiencias anteriores, esta vez la protección obligada no tuvo interrupciones por largo tiempo. La crisis de los '30 empalmó con la Segunda Guerra Mundial y garantizó un prolongado período de retracción del comercio internacional. Estas condiciones, junto a las transformaciones desencadenadas en el ámbito nacional,

\footnotetext{
${ }^{10}$ Las necesidades fiscales del Estado en un marco en el que contaba con escasos instrumentos de recaudación que no estuvieran vinculados al comercio exterior profundizaban aún más las restricciones al comercio que tenían origen en las crisis europeas del capitalismo. Sin embargo, estas decisiones y los debates que generaban se relacionaban más con asuntos de política macroeconómica que industrial (Schvarzer, 2001).
} 
dieron por tierra el consenso liberal y revirtieron profundamente la dinámica social y económica de la Argentina. Una vez terminada la Segunda Guerra Mundial, durante el gobierno peronista, el proceso de industrialización que hasta allí había tenido un carácter más o menos involuntario, se transforma en una industrialización deliberada, apoyada, promovida y sostenida por el Estado.

Autores como Katz y Kosacoff (1989) también coinciden en señalar la existencia de una etapa ISI antes del '30, que no puede ser entendida sino bajo esta primera acepción de prácticas sustitutivas. En su ejercicio de periodización del crecimiento industrial argentino, señalan una "primera etapa" de la ISI que se sitúa desde la mitad o el último tercio del siglo XIX y hasta el período de entre guerras. Para los autores, una segunda etapa comprendería el tiempo desarrollado hasta la llegada del Peronismo y una tercera comprendería la experiencia del peronismo en el gobierno. No es nuestra intención asumir o hacer propia esta periodización, sino dar cuenta de la manera en que, al momento de elaborar caracterizaciones de la industria de los años previos a la década del ' 30 , los autores hacen referencia a la ISI; al tiempo que asumen que estos procesos sustitutivos se operan bajo el modelo de desarrollo agroexportador —o modelo de desarrollo "hacia afuera"- Esto, sin perjuicio de reconocer que las industrias más dinámicas estaban vinculadas al procesamiento y a la exportación de bienes relacionados a la producción agropecuaria, que ordenaba la economía del país.

A pesar de las diferencias o coincidencias en la profusa literatura existente, resulta para nosotros aclarado que, aunque tenemos una industrialización llevada a cabo mayormente en contra de la política económica que sostenía el modelo agroexportador y luego una industrialización promovida por el Estado, pero en contra del consenso internacional de las ideas económicas, en ambas se pueden reconocer procesos sustitutivos de industrialización. Estos pueden haber dependido más "libremente" de los "empresarios industriales" en un período que en otro, pueden haber tenido una relevancia distinta al interior del desarrollo industrial, o incluso pueden haber asumido un rol diferenciado respecto al conjunto de la economía nacional. En todos estos momentos, sin embargo, aparece una práctica económica que se nombra de igual manera que a la estrategia de desarrollo -que, por estos años, aún no se había formulado como tal-o a la etapa histórica que se abre, de acuerdo al consenso historiográfico, con la crisis de los años ' 30 .

En síntesis, hemos destacado ya la importancia de distinguir con claridad la industrialización como fenómeno microeconómico producido por el impulso y la decisión de agentes económicos privados en el marco de un modelo económico orientado a importar antes que producir estos bienes manufacturados, de aquella promovida por la política económica y desarrollada en el marco de un modelo que la pone como uno de los ejes del desarrollo nacional. Así, se expresa claramente que la sustitución de importaciones puede existir independientemente del modelo de desarrollo vigente, las condiciones de la economía o las características del patrón de acumulación. En este sentido, su existencia es independiente del grado de desarrollo general de la economía de referencia, siempre que esta no se encuentre produciendo bienes industriales con tecnología de punta o a partir de desarrollo técnico endógeno. De esta forma, la 
Reche. La Industrialización por Sustitución de Importaciones (ISI): usos y sentidos de una expresión polisémica

determinación de la conveniencia o no de la sustitución, será resuelta por un cálculo de economicidad en que cada perspectiva teórico-política ponderará elementos diferentes. Sin embargo, en el sentido expresado en este apartado, la única razón que justifica el desarrollo de industrias sustitutivas se encuentra en las decisiones microeconómicas de los agentes económicos. Así, esta acepción de industrialización sustitutiva de importaciones señala un uso que refiere al proceso sustitutivo más allá y más acá del período denominado ISI en la historia económica argentina.

\section{La industrialización sustitutiva de importaciones como período de la historia argentina}

De acuerdo con nuestro argumento, la expresión industrialización por sustitución de importaciones funciona igualmente como denominación de un periodo de la historia económica nacional. En muchos países, cuyas economías se encontraban ordenadas por la actividad primario-exportadora - sea esta agropecuaria o minera-, este período puede distinguirse por el rápido crecimiento económico impulsado por el desarrollo de una industria orientada al mercado interno. Hemos planteado, en el apartado anterior, que gran parte de las prácticas sustitutivas habían sido estimuladas por restricciones externas, sin importar si estas eran independientes o externas a la dinámica nacional o decididas y generadas por los Estados. Así, en diversos países, la historiografía ha denominado al período de industrialización que se desarrolló ya entrado el siglo XX como "etapa ISI".

En la región latinoamericana, este proceso adquirió rasgos claramente distintos durante el período que va desde la segunda mitad del siglo XIX hasta nuestros días. A pesar de que, como afirman Katz y Kosacoff (1989), en la historiografía argentina las líneas divisorias no resulten tan claras, se ha distinguido convencionalmente entre primera y segunda ISI, o entre la industrialización liviana y pesada, o entre la predominancia de una industria extensiva o intensiva, etc. Estas distinciones genéricas proponen, según las perspectivas que sostenga cada investigador, recortes diferentes y marcan puntos de inflexión distintos, así como privilegian acontecimientos y variables heterogéneas. Así, por ejemplo, la coincidencia sobre la distinción entre una primera y una segunda ISI, puede no implicar un acuerdo sobre las características o el desempeño de la economía nacional en estas fases ${ }^{11}$.

Lo cierto es que la industrialización asume etapas que son propias de la complejidad tecnológica de la producción industrial capitalista y, aun sin universalizar las experiencias históricas concretas de los países incorporados a la división internacional del trabajo durante el siglo XIX, en todos ellos presenta algunos rasgos comunes. Estos no refieren a etapas secuencialmente necesarias en el desarrollo industrial, pero sí en los grados de complejidad y desarrollo tecnológico de las formas productivas, de manera

\footnotetext{
${ }^{11}$ No pretendemos elaborar un análisis historiográfico respecto del conjunto de la industrialización argentina. Simplemente, damos cuenta de aquello que pretendemos sostener en relación con lo que los investigadores sociales han denominado ISI; una etapa, un período, o una fase de la historia argentina. Este recurso aparece incluso en la historiografía de otros países -latinoamericanos, por ejemplo-, aunque resulta excesivo pretender su inclusión y abordaje en el marco de este trabajo.
} 
que las connotaciones económicas y sociales de la producción de alimentos difieren radicalmente, por ejemplo, de la siderúrgica.

En consonancia con lo planteado, los historiadores con diferentes e incluso opuestas perspectivas historiográficas reconocen un período de la historia económica nacional al que identifican como de industrialización por sustitución de importaciones. Indudablemente, las diferencias teórico-conceptuales se pueden apreciar en la forma en que caracterizan este período, a partir de los ejes centrales de sus análisis $\mathrm{y}$ en sus ponderaciones de las políticas económicas ${ }^{12}$. Por otro lado, aunque exista un relativamente amplio consenso sobre la datación del período que comienza en la década del '30, no existen las mismas coincidencias respecto de hasta cuándo la ISI se extendería. Aunque recientemente el debate se ha centrado en las características del período abierto en $1976^{13}$, una revisión de la literatura más general permite advertir opiniones según las cuales la ISI habría tenido final con el derrocamiento del gobierno peronista. Otros incluyen los años del desarrollismo frondizista y los de la Revolución Argentina, y otros incluso nombran de esta manera al período que se extiende hasta el golpe de Estado de 1976 o hasta la crisis hiperinflacionaria de 1989. Por ahora, resulta suficiente decir que el período de la historia argentina que comienza con la crisis internacional del '29 y se extiende hasta la segunda posguerra es denominado por un importante grupo de historiadores de la economía argentina como industrialización por sustitución de importaciones. Intentaremos a continuación ejemplificar este significado, dando cuenta del uso que realizan algunos de estos historiadores.

Mónica Peralta Ramos (2007) entiende por industrialización sustitutiva de importaciones a un período en el desarrollo económico argentino, caracterizado por el rol dinámico de la industria en la expansión económica del país. Este período tendría su comienzo con la crisis internacional de 1930, que habría generado condiciones que permitieron una alianza de clases favorable a esta industrialización. Para la autora, el inicial crecimiento industrial limitado no perjudicó a los grupos de interés agropecuario, en tanto no modificó la estructura económica del país centrada en las exportaciones agropecuarias, en coincidencia con el razonamiento de Murmis y Portantiero (1987). Este

\footnotetext{
${ }^{12}$ Una crítica a las perspectivas dominantes sobre el proceso de industrialización en argentina y sus límites puede verse en Sartelli y Kabat (2016). Los autores se distancian y ponen reparos sobre algunos consensos fuertemente establecidos en la literatura local, en la que predominan perspectivas estructuralistas, dependentistas y liberales.

${ }^{13}$ En efecto la interpretación más consolidada en los últimos años ha tendido a resaltar el corte que implicó la última dictadura cívico militar. Sumadamente se ha debatido el supuesto agotamiento de la ISI. Esta periodización y los consensos actuales destacan el proceso de desindustrialización de la economía argentina iniciado en 1976 (Azpiazu y Schorr, 2010; Basualdo, 2006; Rougier y Odisio, 2019). Otros autores han discutido la idea de desindustrialización tal como se presenta en las ciencias sociales argentinas (Grigera, 2011; 2012). Conviene destacar que, aunque el planteo de los críticos a la noción de desindustrialización se refiere a la caracterización de un proceso diferente al tratado en este artículo, sus implicancias repercuten en nuestro asunto. En efecto, en ambos casos -ISI y desindustrialización- se trata de conceptualizaciones ambiguas producto de una sobrecarga semántica. Sin embargo, el señalamiento respecto del carácter polisémico no tiene, en nuestro trabajo la pretensión de ofrecer una interpretación diferente del fenómeno o los fenómenos a los que refiere, sino de destacar que bajo el supuesto paragua conceptual "industrialización sustitutiva" se nombra a asuntos diferentes.
} 
crecimiento industrial estuvo fundado en un proceso de sustitución de importaciones, evidenciado por el hecho de que "el $90 \%$ el crecimiento de la manufactura entre comienzos de la década de 1930 y principios de la de 1960 se explicó por la reducción del coeficiente de importación en la oferta total de productos manufacturados" (Peralta Ramos, 2007, p. 72). Asimismo, según la autora, la industrialización por sustitución de importaciones pasó por dos etapas diferenciadas. Una primera, entre 1930 y 1950, en la que la rama textil y la de alimentos y bebidas representaban el $45 \%$ de la expansión de la producción industrial neta; una segunda etapa del ' 50 al ' 60 , en la que la expansión del sector metalúrgico representó el 57\%, mientras que las ramas líderes de la primera etapa solo lo hicieron en un 9\% (Peralta Ramos, 2007). A diferencia de este período de industrialización sustitutiva, para la socióloga la etapa que va de 1966 a 1976 se orientó por otra alternativa de desarrollo industrial, que

se caracterizó por una sistemática intervención del estado en la economía, a fin de impulsar el desarrollo de las ramas más capital intensivas de la industria. Esta intervención estatal intensificó las restricciones estructurales intrínsecas al modelo de desarrollo industrial en vigencia y obstaculizó la posibilidad de reeditar el modelo distribucionista. (Peralta Ramos, 2007, p. 137)

Como resultado de la intervención estatal directa, el Estado promocionó las exportaciones de las ramas que lideraban en desarrollo industrial -de tipo capital intensivo-.

Para Gerchunoff y Llach (2010, p. 142) también, con la crisis de los ' 30 , se inició un período que "creó nuevas condiciones: la depreciación del peso y las nuevas tarifas trajeron un renacimiento industrial que encontró luego protección en el control de cambios". Según los datos proporcionados por los autores, las importaciones cayeron, en una década, de un $34 \%$ a un $22 \%$ como porcentaje de la producción industrial total. Sin embargo, se concentran más en analizar las características y fallas de la industrialización peronista que en sopesar la evolución general del proceso industrial (Gerchunoff y Llach, 2010, pp. 215 y ss).

Por su parte, Belini y Korol (2012, p. 94) sostienen que

en la década de 1930 el sector industrial se convirtió en el motor de la economía argentina, papel que continuaría desempeñando durante los cuarenta años siguientes. En un primer momento, el impulso de la industrialización sustitutiva de importaciones fue resultado del efecto combinado de la devaluación de la moneda del orden del $40 \%$ entre el ' 28 y '32, la elevación de los aranceles en 1931 y la imposición de controles cambiarios y controles previos.

Estas intervenciones, sin embargo, no se implementaron como parte de una política industrial coherente y ordenada, por el contrario, esta industrialización resultó como "una consecuencia inevitable de la Gran Depresión” (Belini y Korol, 2012, p. 97). Además, y en 
coincidencia con los autores ya citados, destacan que las ramas más relevantes dentro de la estructura industrial fueron las de alimentación, bebidas y tabaco, textiles, confecciones y cuero que representaban el $50 \%$ de la producción industrial total y más de un tercio del valor agregado. Asimismo, refieren al carácter concentrado de la estructura industrial en desarrollo "en manos de un número reducido de grandes empresas, muchas de ellas de origen extranjero y la existencia de un nutrido grupo de pequeñas y medianas firmas y talleres que empleaban un número menor de personal y tenía una participación menos destacada en el valor de la producción” (Belini y Korol, 2012, p. 100).

Por otra parte, para Basualdo (2006a, p. 27),

en los años treinta, la protección arancelaria y las restricciones en el mercado cambiario impuestas por la situación del sector externo impulsaron un aceleramiento del proceso de industrialización basado en la sustitución de importaciones, consolidándose un elevado grado de concentración económica, tanto en términos de producción como del empleo sectorial.

Aun así, según este autor, recién con la llegada del peronismo al gobierno "el modelo agroexportador quedó atrás, y se fortaleció la industrialización" (Basualdo, 2006, p. 34). Esta experiencia de industrialización combinó el crecimiento económico con un importante aumento de la participación de los trabajadores en el ingreso, donde el salario funcionó como un potente e insustituible factor de demanda; al tiempo que los mecanismos de protección arancelaria y pararancelaria permitieron aminorar su significación en la estructura de costos de los bienes producidos.

La salida del peronismo del poder dio por cerrada esta primera etapa de la ISI. Posteriormente, se combinaron elementos de orden interno e internacional que propiciaron un conjunto de mutaciones en la dinámica de industrialización. Para Basualdo (2006b, p. 123),

durante el gobierno desarrollista de A. Frondizi-Guido (19581964), con posterioridad al golpe de Estado que interrumpió el segundo gobierno del peronismo en 1955, se puso en marcha la segunda etapa de sustitución de importaciones sobre la base de una significativa incorporación de inversiones extranjeras que se localizaron en la actividad industrial, principalmente en la producción automotriz, metalúrgica y química-petroquímica.

A su vez, en esta segunda etapa de ISI, puede diferenciarse esta primera época de aquella que va de 1963-1974 en que se produjo un funcionamiento pleno a partir de la consolidación de la expansión industrial. Esta, aunque no logró "la desaparición del desfasaje entre el estancamiento de la producción de bienes exportables y el mayor dinamismo relativo de la demanda de bienes importados por parte del sector industrial" (Basualdo, 2006b, p. 124), atenuó de manera significativa la intensidad y duración de los ciclos económicos. 
Reche. La Industrialización por Sustitución de Importaciones (ISI): usos y sentidos de una expresión polisémica

Neffa (1998, p. 124) coincide en que

durante esta etapa, de 1930 a 43, la economía argentina vivió un profundo proceso de transición que modificó substancialmente la estructura del sistema productivo. Se había alcanzado previamente los límites de la frontera agrícola (...), incrementado la población y consiguientemente la demanda interna de productos agropecuarios (...) que disminuyeron los saldos exportables y con ellos la capacidad para importar.

Estos cambios, al restringir de manera duradera las posibilidades de importar productos industriales de los países centrales, explican el fuerte crecimiento de la producción industrial nacional orientada al mercado interno, a partir de entonces, a un ritmo superior al del PBI. Esta modificación sustantiva de la estructura productiva dio paso a un período en el que la actividad industrial se constituyó como motor de la economía argentina, y al que denomina de industrialización por sustitución de importaciones.

Puede resultar confusa la manera en que Neffa $(1998,1999)$ extiende la ISI hasta 1989. En verdad, se produce aquí la combinación de dos elementos. Por ahora destacaremos que, así como plantea la existencia de una primera etapa de la ISI previa a los '30, también propone la existencia de una cuarta etapa desde 1976. Al margen de las consecuencias interpretativas que se derivan de las afirmaciones del autor, creemos que estas "etapas" lo son del proceso sustitutivo y no de la economía nacional. Aquí se evidencia la forma en que la polisemia de la expresión ISI confunde las etapas, los modelos de desarrollo y el proceso sustitutivo. Aunque nos muestra un abordaje en que la acepción ISI se refiere a la práctica económica, puesta al lado de "etapa", esta expresión termina por confundir a cualquier lector. Sin embargo, resulta explícito que es posible identificar un uso que refiere al proceso sustitutivo más allá y más acá del período ISI - al que nos hemos estado refiriendo- de la historia nacional. Este hecho no niega que Neffa también asuma la existencia de una etapa ISI, dado que, si hubo sustitución de importaciones durante los años del modelo agroexportador o durante la última dictadura militar, esta no tuvo el volumen, la relevancia, ni el dinamismo que tendría entre 1930 y 1976.

Hasta donde hemos conseguido avanzar, resulta indiscutible que la expresión industrialización por sustitución de importaciones refiere en ocasiones a determinados "procesos de industrialización sustentados y hegemonizados por aquellas producciones que, sobre la base de una demanda interna preexistente, tiende a sustituir las importaciones requeridas para su atención" (Azpiazu, 2008, p. 379). Como todos los autores citados han permitido mostrar, más allá de sus diferentes perspectivas, este proceso se inició en Argentina -y en general en América Latina- como un fenómeno casi "natural", derivado indirectamente de los efectos de la disminución del comercio internacional y las dificultades para importar, fortalecidas por las intervenciones estatales que procuraban controlar la salida de unas divisas restringidas por la baja de las exportaciones. Así, 
las políticas estatales que cohibieron las importaciones y las rigideces en el mercado internacional configuraron un escenario propicio, que se mantuvo durante un largo período a partir de la crisis de 1929, para el desarrollo de la industria local. Este proceso, que resulta generalizado en la década del 30 y da su nombre al período que allí comienza, es denominado "etapa de industrialización por sustitución de importaciones". Aunque no hemos incursionado en el carácter o la relevancia explicativa otorgada por las diferentes perspectivas a las dimensiones y variables analizadas, resulta cierto que cada uno de los sentidos y las caracterizaciones de la "etapa ISI" expresa la existencia de un campo de debates en el cual se expresan formas distintas de comprender el período histórico.

\section{Los estudios sobre el desarrollo económico en América Latina y la industrialización sustitutiva como estrategia de desarrollo}

Por último, la industrialización sustitutiva hace referencia a una programática teórico-económica orientada al desarrollo social y económico nacional sobre el eje del crecimiento industrial del país, impulsado por sectores o ramas en que se difunden procesos sustitutivos y que permiten una mayor apropiación del progreso técnico. Surgida del análisis de las condiciones de desarrollo de los países subdesarrollados de Latinoamérica durante los ' 50 del siglo pasado, esta estrategia de desarrollo fue elaborada a partir de la firme convicción de que una economía proveedora de materias primas -bienes agropecuarios y mineros- solo reproduciría una situación de atraso y rezago económico. La importancia que esta programática asumió en América Latina podrá notarse tanto en las ideas económicas de la región como en el diseño de políticas estatales y en los debates intelectuales. Desde su mirada regional, destacaba la centralidad de la industria para el desarrollo económico y propugnaba una acción del Estado dirigida a producir transformaciones más o menos profundas en la estructura productiva que impulsaran, acompañaran y protegieran el surgimiento y crecimiento de industrias sustitutivas como primer paso de la industrialización. De esta manera, se pretendía que el desarrollo industrial consiguiera modificar la situación de atraso a que estaban condenados los países latinoamericanos dada su particular inserción en la división internacional de trabajo (DIT).

Asimismo, estas indagaciones adquirieron un fuerte impulso en el pensamiento económico latinoamericano a partir de la constitución de un campo propio de investigación alrededor del denominado "desarrollo del subdesarrollo" (Nahón, Rodríguez, y Schorr, 2006) durante los '50 y los '60 del siglo pasado. La expresión genérica de "teoría del desarrollo latinoamericana" reúne a un conjunto complejo y diverso de perspectivas teórico-políticas que nacieron en aquellos años sobre un eje común de reflexión vinculado a la posibilidad y estrategia de desarrollo de los países latinoamericanos (Guillén, 2008). Sus más importantes expresiones, el estructuralismo latinoamericano, el desarrollismo y la teoría de la dependencia anudaron un campo de investigaciones interdisciplinario de las ciencias sociales, que marcaron fuertemente al pensamiento social latinoamericano e, incluso, signaron el proceso de "surgimiento" e institucionalización de las disciplinas sociales en Argentina (Beigel, 2010). Este 
Reche. La Industrialización por Sustitución de Importaciones (ISI): usos y sentidos de una expresión polisémica

fructífero campo de investigación, profundamente comprometido con su presente histórico, estableció una particular relación con la confección de políticas a partir del fuerte vínculo con organismos estatales - y con el poder político- o con organismos supranacionales, destinados a asesorar y recomendar en materia económica a los países de la región. Este movimiento intelectual y político tendrá una presencia importante hasta las dictaduras latinoamericanas que se extendieron entre mediados de los setenta y mediados de los ochenta. Con la recuperación democrática en la mayoría de los países latinoamericanos, las discusiones económicas y los protagonistas de esos debates cambiaron radicalmente ${ }^{14}$.

En este apartado, esbozaremos una breve presentación de la perspectiva desarrollada por el estructuralismo latinoamericano, corriente más importante y representativa del pensamiento económico regional, a fin de precisar sus planteos y evidenciar el uso de la expresión industrialización por sustitución de importaciones como programática económico-política. Tal como en los apartados anteriores, no pretendemos elaborar una síntesis ni sistematización de la perspectiva de la Comisión Económica para América Latina (CEPAL de aquí en adelante) de la Organización de Naciones Unidas (ONU); Nos conformamos con poder mostrar la manera en que la industrialización sustitutiva se presenta como estrategia de desarrollo.

Ciertamente, el pensamiento latinoamericano asumió y procesó la pregunta por el desarrollo del subdesarrollo de manera independiente y crítica, y adquirió un carácter propio a partir del surgimiento del estructuralismo latinoamericano. Esta nueva perspectiva se distinguió por su rechazo a la teoría ricardiana de las ventajas comparativas y las virtudes del comercio internacional para las economías subdesarrolladas (Nahón et al., 2006), ahora difundidas y promovidas por la teoría de la modernización. Esta línea de pensamiento impulsada por Raúl Presbich, quien fue además su más grande exponente, tuvo como soporte institucional principal a la CEPAL. Las formulaciones de Prebisch respecto al vínculo entre los países periféricos y centrales permitieron una caracterización novedosa sobre la situación de las economías latinoamericanas, y se constituyó en el núcleo teórico-político fundante y distintivo de esta corriente de pensamiento ${ }^{15}$. Más aún, esta caracterización resultó fundamental para el conjunto del pensamiento económico latinoamericano, en la medida que permitió no solo el desarrollo del pensamiento estructuralista cepalino, sino también se constituyó en un antecedente necesario para las perspectivas dependentistas, desarrolladas posteriormente.

Prebich, verdadero pionero de la teoría y práctica del desarrollo económico, formuló las bases de la teoría del desarrollo latinoamericano desde una constatación empírica que permitía elaborar una sólida crítica a la teoría clásica del comercio internacional, responsable de la justificación del lugar económico de los países latinoamericanos en la división internacional del trabajo vigente. Advirtió que la premisa

\footnotetext{
${ }^{14}$ Sobre estos cambios, puede verse, para el ámbito latinoamericano, Vidal y Guillén (2008).

${ }^{15}$ Si bien el uso del concepto centro-periferia representa un elemento central tanto de la teoría de la economíamundo desarrollada por Braudel (1979) y Wallerstein (1998), como de la teoría del imperialismo, la originalidad de Prebisch consistió en construir -sobre la base de este concepto- una teoría del desarrollo del subdesarrollo.
} 
sobre la que se basaba la DIT, según la cual el fruto del progreso técnico tiende a repartirse parejamente entre toda la colectividad, era absoluta y terminantemente contradicha por la realidad (Prebisch, [1949] 1986). Según su propia constatación empírica ${ }^{16}$, expuesta en lo que luego se consideró un texto fundacional para esta perspectiva ${ }^{17}$, los precios de bienes industriales y los precios de los bienes agropecuarios habían evolucionado contrariamente a lo esperado, bloqueando cualquier posibilidad de transmisión del progreso técnico desde los países industrializados — que lograban aumentar constantemente la productividadhacia los países de la periferia del sistema económico mundial, que importaban estos bienes industriales a cambio de producción primaria.

El deterioro de los términos de intercambio para los países productores de alimentos y materias primas expresaba una situación que daba por tierra las bases de la teoría del comercio internacional, "desde los años setenta del siglo pasado [siglo XIX], hasta antes de la Segunda Guerra Mundial, la relación de precios se ha movido constantemente en contra de la producción primaria" (Prebisch, [1949] 1986, p. 482). Así, de acuerdo con el argumento central,

aunque la productividad en la producción de manufacturas en el centro era superior a la productividad en la producción de productos primarios en la periferia, lo que haría suponer, de acuerdo a la teoría tradicional, una baja en los precios de las manufacturas mayor que la registrada en los productos primarios, las cosas se desenvolvían en el sentido opuesto (Guillén, 2008, p. 496).

Los países perjudicados no solo no participaban de las ventajas de los aumentos de productividad de los centrales, sino que además no lograban retener íntegramente los frutos de su propio progreso técnico, ya que parte de este se veía directamente traspasado a los países centrales donde "los ingresos de los empresarios y factores productivos han crecido (...) más que el aumento de la productividad” (Prebisch, [1949] 1986, p. 483). De esta manera, los supuestos y argumentos en que se basaba la clásica teoría del libre comercio resultaban inaplicables a los países en desarrollo o periféricos y a su especial relación con los países desarrollados del centro (Pérez Caldentey et al., 2000), al tiempo que se ponía en aprietos a la teoría de las ventajas comparativas (Guillén, 2008).

La díada centro-periferia debe entenderse, en el marco de este enfoque adoptado por la CEPAL, como una formulación que pretende caracterizar unas particulares estructuras socioeconómicas y explicar la forma en que un polo de la economía mundial progresa y el otro se rezaga (Pérez Caldentey et al., 2000). Estos países rezagados, que se ubican en la periferia del sistema económico mundial, son llamados "periféricos" en oposición a los denominados "centrales". La condición periférica de los países latinoamericanos, lejos

\footnotetext{
${ }^{16}$ Un desarrollo paralelo, sobre el deterioro de los términos de intercambio, es el de Singer (1950).

${ }^{17}$ Nos referimos a El desarrollo económico de la América Latina y algunos de sus principales problemas, publicado por primera vez en 1949. Las citas y referencias utilizadas en este trabajo corresponden a Prebisch, R. ([1949] 1986). El desarrollo económico de la América Latina y algunos de sus principales problemas. Desarrollo Económico, 26(103), 479-502.
} 
de ser entendida como rezago o atraso en un camino lineal y universal al desarrollo, es asumida como resultante del mismo proceso histórico que forjaba la centralidad de los países del norte atlántico. Así el subdesarrollo dejaba de pensarse como una ausencia de, o condición previa a, para ser entendido como resultado de una dinámica socio económica y política de la que difícilmente los países latinoamericanos saldrían sin transformaciones profundas de sus economías. En efecto, la tendencia al deterioro de las condiciones de intercambio de las exportaciones de productos primarios y la disparidad de la elasticidad de la demanda de importaciones de centro y periferia, son manifestaciones de la desigualdad entre productores/exportadores de bienes manufacturados y de bienes primarios, que reproduce sistemáticamente la disparidad en la difusión internacional del progreso técnico y la distribución de sus frutos.

En la medida que problema básico del desarrollo económico era, para la perspectiva original de la CEPAL, la elevación del nivel de productividad del conjunto de la fuerza de trabajo, la industrialización tendría un papel de trascendencia en tanto absorbe mano de obra que queda marginada del proceso productivo agropecuario. Incrementa así la productividad de grandes masas de trabajadores, fundamentalmente de aquellos que, por estar asociados a actividades artesanales domésticas, desarrollaban su trabajo con niveles muy bajos de productividad y eleva el nivel general de empleo. Sobre esta base, se critica el modelo de desarrollo agroexportador, destacando la necesidad de impulsar el desarrollo industrial nacional; "el MPE [modelo primario exportador] no tenía ninguna viabilidad en el mundo de la posguerra, por lo que resultaba imperioso emprender el camino de la industrialización" (Guillén, 2008, p. 496), que pasaría a ser "la forma principal y obligada de crecimiento en las economías que constituyen el polo periférico de dicho sistema [centro-periferia]" (Rodríguez, 1980, p. 36).

Poco antes de su muerte, en un texto breve, pero de gran valor ${ }^{18}$, el fundador de estructuralismo cepalino observa retrospectivamente sus ideas. En él, resume los trazos más importantes de su desarrollo intelectual y afirma:

mi diagnóstico de la situación de los países latinoamericanos se basó en mi crítica del patrón de desarrollo orientado hacia afuera, que en mi opinión no permitía el desarrollo pleno de tales países, la política de desarrollo que propuse se orientó hacia el establecimiento de un nuevo patrón de desarrollo que permitiría superar las limitaciones del patrón anterior: esta nueva forma de desarrollo tendría como objetivo principal la industrialización (...) [De este análisis] surgió la conclusión de que la sustitución de importaciones estimulada por una política de protección moderada y selectiva es un procedimiento económicamente sensato para el logro de los siguientes efectos deseables: a) (...) corregir la tendencia hacia una restricción externa al desarrollo (...) b) (...) [contrarrestar] la tendencia

\footnotetext{
${ }^{18}$ Dicho texto fue publicado en español en 1983 en El Trimestre Económico. Posteriormente, en Prebisch,
} R. (1987). Cinco etapas de mi pensamiento sobre el desarrollo. Comercio Exterior, 37 (5), 345-352. 
hacia el deterioro de las condiciones de intercambio. (Prebisch, 1987, pp. 346-347) [Los agregados nos pertenecen].

Así, la industrialización se presentaba como el principal medio ${ }^{19}$ para captar los frutos del progreso técnico y elevar los estándares de vida de la población, en tanto conllevaría una modernización general de la vida social y el desarrollo económico de la periferia (Sunkel, 2011). Por esto, el modelo de desarrollo propuesto por Prebisch e impulsado por la CEPAL, "otorgaba prioridad al estado como pivote y actor clave del desarrollo económico, priorizando una política de sustitución de importaciones apoyada y estimulada por una política industrial vertical" (Pérez Caldentey et al.; 2000, p. 16) ${ }^{20}$. Según esta formulación teórica inicial de la CEPAL (Prebisch, [1949] 1986; CEPAL, 1951), la industrialización por sustitución de importaciones constituía el principal mecanismo para la superación del subdesarrollo de las economías latinoamericanas.

Tal como destaca Fitzgerald (1998), la propuesta estructuralista de industrialización sustitutiva diseñaba un estilo de desarrollo integral que daba cuenta, al mismo tiempo, de las cuestiones relacionadas al crecimiento, la inversión, el empleo y la distribución del ingreso. Los objetivos centrales del esquema de industrialización propuesto "pasaban por generar un importante ahorro de divisas en un mediano plazo, dar respuestas a la situación del mercado laboral y favorecer el progreso técnico" (Nahón et al., 2006, p. 338). Según señala Sunkel (2000), este tema estuvo presente

desde el comienzo en la preocupación de la institución, pero más bien como el área moderna, innovativa, productiva, de futuro, cuya promoción debía llenar un vacío en la estructura productiva incompleta (...). Este sector debía convertirse en el motor del desarrollo mediante la introducción del avance tecnológico y los aumentos de productividad. (p. 36)

De esta manera, en la inmediata posguerra, el esfuerzo del estructuralismo latinoamericano formulado por Prebisch pretendió, desde la base de una formulación teórica propia y para el conjunto del subcontinente, proponer el marco de una estrategia de desarrollo que permitiera la reversión de la situación socioeconómica en que se encontraban la mayoría de los países. Este modelo de desarrollo por medio de la industrialización por sustitución de importaciones quizás no fue, como afirma Fitzgerald

\footnotetext{
${ }^{19}$ Es importante destacar que la industrialización no se presenta como una receta mágica y aislada. En verdad, la propuesta de desarrollo para América Latina formulada originalmente por la CEPAL se estructuraba alrededor de cuatro elementos interrelacionados: la industrialización por sustitución de importaciones, la reforma agraria, la intervención estatal y la integración económica latinoamericana (Cf. Nahón et al., 2006, p. 337-340). Aun así, la preponderancia de cada elemento irá variando con el tiempo y resulta claro que durante la primera etapa la expectativa principal se ubica en la industrialización sustitutiva (Farruggia, 2000).

${ }^{20}$ Farruggia $(2000$, p. 287) también afirma que "el enfoque estructural de la CEPAL que dio origen a la implementación del modelo de Industrialización Sustitutiva en América Latina entre 1960 y 1980", y asumía que este debía ser el eje de la política económica del estado. En verdad, esta estrategia de desarrollo "sería posible solo con la intervención del estado que llevara a cabo la conducción del proceso por medio de la planificación" (Farrugia, 2000, p. 277).
} 
Reche. La Industrialización por Sustitución de Importaciones (ISI): usos y sentidos de una expresión polisémica

(1998), propiamente una estrategia de desarrollo sino una lectura de lo que ocurría en los hechos. El debate es complejo en la medida que las posiciones del propio Prebisch irán cambiando y son, en algunos puntos, opuestas. Nada de esto puede negar, sin embargo, el relevante papel cumplido por la CEPAL en el diseño de políticas y en el asesoramiento a los países de la región en relación a sostener una estrategia de industrialización sustitutiva. La CEPAL ha quedado asociada verdaderamente a este importante legado. Quizás, poco tiempo después, la propia perspectiva cepalina comenzó a complejizar los análisis a partir del reconocimiento respecto a las dificultades que prevalecían y se profundizaban con la industrialización sustitutiva ${ }^{21}$. Aun así, lo cierto es que en el momento de su planteo original se enfrentó deliberadamente con las perspectivas clásicas del desarrollo y del comercio internacional, pensadas en los países centrales, sosteniendo la necesidad del desarrollo industrial de los países subdesarrollados.

Hasta aquí, el carácter secuencial de la presentación seguida resalta el hecho de que seguramente esta construcción teórica fue, en realidad, una práctica antes de ser una política y una política antes de ser una teoría. Como lo afirma el mismo Prebisch (1987, p. 346), "la política económica que yo proponía trataba de dar una justificación teórica para la política de industrialización que ya se estaba siguiendo (sobre todo en los países grandes de América Latina), de alentar a los otros países a seguirla, y de proporcionar a todos ellos una estrategia ordenada para su ejecución".

\section{Comentarios finales}

La pregunta orientadora del presente trabajo nos empujó a explorar, más que definiciones o precisiones conceptuales sobre la ISI, diferenciaciones de usos con los que opera una fórmula harto reiterada en las producciones de los investigadores sociales latinoamericanos. Nuestro argumento principal, planteado al comienzo de este trabajo, es que la expresión tiene un marcado carácter polisémico en la medida en que puede

\footnotetext{
${ }^{21}$ Las nuevas dificultades de las economías latinoamericanas en los años '50 y '60 fueron revelando progresivamente las limitaciones del desarrollo industrial periférico. Al interior de la propia perspectiva cepalina surgieron fuertes criticas orientadas por la desazón que provocaron las recurrentes crisis económicas y políticas de los países latinoamericanos. Juntamente, y bajo la influencia de otras perspectivas teóricas, la crítica a la realidad latinoamericana adquirió nuevos sentidos y profundidades que comenzaron a negar la posibilidad de salir del subdesarrollo debido al carácter dependiente de las economías locales. En efecto las perspectivas dependentistas avanzaron, sobre la base de los aportes del estructuralismo, en reconocer el carácter dependiente de las economías latinoamericanas en el marco del funcionamiento global del capitalismo. Así, la propia industrialización periférica no solo resultaba infructuosa a la hora de revertir las dificultades, sino que tendía a reproducirlas a partir de las limitaciones que tenían origen en su carácter dependiente. Aportes más cercanos en el tiempo, como los de Katz y Kosacoff (1989) o de Notcheff (1994), han precisado las limitaciones de la industrialización sustitutiva que se desarrolló, por ejemplo, en Argentina. En este caso, los autores señalan que los productos que iniciaron la sustitución de importaciones resultaban copias de diseños extranjeros atrasados respecto de las innovaciones técnicas y los cambios internacionales y que la industrialización por sustitución de importaciones respondió a un comportamiento tecnológico adaptativo y tardío respecto a los países más avanzados. Así, el escaso desarrollo tecnológico local impidió que las transformaciones del sector industrial fueran lo suficientemente profundas y quebrantaran la dependencia tecnológica con el exterior.
} 
referir a tres fenómenos diferentes: una práctica económica, un período histórico y una estrategia de desarrollo.

En síntesis, hemos mostrado que la industrialización por sustitución de importaciones puede hacer referencia a, por ejemplo, una forma específica de industrialización desarrollada en algunos países en que los procesos industriales se adquirieron por difusión. Sin embargo, estas prácticas sustitutivas pueden consolidar un proceso que se expresa en una variedad de regiones del mundo, más allá y más acá de las etapas denominadas de industrialización por vía de la sustitución de importaciones. Latinoamérica experimentó centralmente esta forma específica de industrialización, aunque no le es exclusiva. Tampoco solo por esta vía se produjo la industrialización en los países del subcontinente. Pero allí donde sucedió, su momento de mayor relevancia, sea porque las políticas económicas estuvieron orientadas en este sentido o porque este sector de la economía asumió un papel dinámico y ordenador del crecimiento económico, fue nombrado etapa de industrialización por sustitución de importaciones.

En parte, la complejidad de los debates sobre el desarrollo en la región se encuentra en la manera en que las experiencias de industrialización estuvieron atravesadas y en tensión con las propuestas programáticas de la CEPAL. Esta institución, de un rol único y trascendente, permeó al conjunto del pensamiento sobre el desarrollo en América Latina. La propuesta de industrialización sustitutiva de Prebisch, sin embargo, mutaría con el tiempo. Por otra parte, disputará su preponderancia con otras ideas sobre el desarrollo industrial presentes en los países latinoamericanos.

Algunos de los temas que hemos transitado esperan abordajes específicos, dedicados y sistemáticos. Otros han sido enormemente visitados y la bibliografía básica resulta inabordable en un trabajo con las pretensiones del nuestro. Con todo, creemos haber demostrado en estas páginas nuestro planteo, aun a sabiendas de que hemos abordado un conjunto de problemáticas que requerirían más atención y precisión.

La misma distinción argumentada, quizás, sea un punto interesante desde el que poder volver y revisar algunos debates que aquí hemos pasado sin detenernos. Sin embargo, las pretensiones de este trabajo se encuentran cumplidas en tanto la distinción presentada resultará útil, según creemos, al momento de abordar otras discusiones teóricas e historiográficas de sumo interés como, por ejemplo, la relativa a la tesis del agotamiento del modelo sustitutivo.

\section{Referencias Bibliográficas}

Arceo, E. (2003). Argentina en la periferia próspera. Renta internacional, dominación oligárquica y modo de acumulación. Buenos Aires: UNQui/FLACSO/IDEP.

Azpiazu, D. (2008). Industrialización sustitutiva. En T. Di Tella et al., Diccionario de ciencias sociales y politicas (pp. 379-381). Buenos Aires: Emecé.

Azpiazu, D. y Schorr, M. (2010). Hecho en Argentina. Industria y economía, 19762007. Buenos Aires: Siglo XXI. 
Reche. La Industrialización por Sustitución de Importaciones (ISI): usos y sentidos de una expresión polisémica

Bagchi, A. K. (1993). Industrialización. En J. Eatwell, M. Milgate y P. Newman (comps.), Desarrollo económico (pp. 287-307). Barcelona: Icaria.

Basualdo, E. (2006a). Estudios de historia económica Argentina: desde mediados del siglo XX a la actualidad. Buenos Aires: Siglo XXI.

Basualdo, E. (2006b). La reestructuración de la economía argentina durante las últimas décadas de la sustitución de importaciones a la valorización financiera. En E. Basualdo y E. Arceo, Neoliberalismo y sectores dominantes. Tendencias globales y experiencias nacionales (pp. 123-177). Buenos Aires: CLACSO.

Beigel, F. (2010). Autonomía y dependencia académica: universidad e investigación científica en un circuito periférico: Chile y Argentina, 1950-1980. Buenos Aires: Biblos.

Belini, C. y Korol, J. C. (2012). Historia económica de la Argentina en el siglo $X X$. Buenos Aires: Siglo XX.

Berg, M. (1987). La era de las manufacturas, 1700-1820: una nueva historia de la revolución industrial británica. Barcelona: Crítica.

Braudel, F. (1979). Civilisation matérielle, économie et capitalisme (Tomos I-III). París: Folio. Caravaca, J. (2011). ¿Liberalismo o intervencionismo? Debates sobre el rol del Estado en la economía argentina, 1870-1935. Buenos Aires: Editorial Sudamericana.

CEPAL (1951). Estudio económico de América Latina. 1949. Nueva York: Naciones Unidas.

Chiaramonte, J. C. (1986). Nacionalismo y liberalismo económicos en Argentina: 18601880. Buenos Aires: Hyspamerica,

Chiaramonte, J. C. (1991). Mercaderes del litoral. Economía y sociedad en la provincia de Corrientes, primera mitad del siglo XIX. Buenos Aires: Fondo de Cultura Económica.

Cipolla, C. M. (1979). Historia económica de Europa (6 vols.). Barcelona: Ariel.

Cornblit, O. E., Gallo, E. y O'connell, A. (1962). La Generación del 80 y su proyecto: antecedente y consecuencias. Desarrollo Económico, 1(4), pp. 5-46.

Cortés Conde, R. (1965). Problemas del crecimiento industrial (1870-1914). En T. Di Tella, G. Germani y J. Graciarena (comps.), Argentina, sociedad de masas. Buenos Aires: Eudeba.

Cortés Conde, R. (1997). La economía argentina en el largo plazo. Buenos Aires: Sudamericana - Universidad de San Andrés.

Di Tella, G. y Zymelman, M. ([1961] 1967). Las etapas del desarrollo económico argentino. Buenos Aires: Eudeba.

Diamand, M. (1973). Doctrinas económicas, desarrollo e independencia: economía para las estructuras productivas desequilibradas: caso argentino. Buenos Aires: Paidós.

Díaz Alejandro, C. (1975). Ensayos sobre historia económica argentina. Buenos Aires: Amorrortu.

Dorfman,A. ([1942] 1970). Historia de la industria argentina. Buenos Aires: Solar/Hachette. Farruggia, O. (2000). Reforma, revolución y adaptación a la economía mundial. Hitos en el pensamiento económico latinoamericano. CEPAL, dependencia y enfoques actuales. La Trama de la Comunicación, 5, pp. 275-293.

Félix, D. (1987). Tendencias en las preferencias del consumidor y desarrollo económico en la industrialización de los siglos xix y xx. Investigación Económica, 46(181), pp. 107-127. 
Ferrer, A. ([1973] 2000). La economía argentina. México: Fondo de Cultura Económica. Fitzgerald, V. (1998). La CEPAL y la teoría de la industrialización. Revista de la CEPAL, No extraordinario, pp. 47-61. Recuperado de http://repositorio.cepal.org/ handle/11362/37962.

Gerchunoff, P. y Llach, L. (2010). El ciclo de la ilusión y el desencanto. Un siglo de políticas económicas argentinas. Buenos Aires: Ariel.

Gerschenkron, A. (1973). Atraso económico e industrialización. Barcelona: Ariel.

Grigera, J. (2011). La desindustrialización en Argentina ¿Agresión a la manufactura o reestructuración capitalista? En A. Bonnet (comp.) El país invisible. Debates sobre la argentina reciente (pp. 81-101). Buenos Aires: Peña Lillo/Continente.

Grigera, J. (2012). El concepto de desindustrialización como peculiaridad argentina. Revista de Estudios Maritimos y Sociales, (5/6).

Guillén, A. (2008). La teoría latinoamericana del desarrollo. Reflexiones para una estrategia alternativa frente al neoliberalismo. En G. Vidal y A. Guillén (coords.), Repensar la teoría del desarrollo en un contexto de globalización. Homenaje a Celso Furtado (pp. 489-518). Buenos Aires: CLACSO.

Hobsbawm, E. (2007). La era de la revolución, 1789-1848. Buenos Aires: Crítica.

Katz, J. y Kosacoff, B. (1989). Las etapas de la industrialización argentina. En J. Katzy, J. B. Kosacoff (Eds.), El proceso de industrialización en la Argentina. Evolución, retroceso y prospectiva. Buenos Aires: CEAL.

Lewis, C. (1991). La industria en América Latina antes de 1930. En L. Bethell (ed.), Historia de America Latina 7. América Latina: economía y sociedad, 1870-1930. Barcelona - Cambridge: University Press - Crítica.

Llach, J. J. (1985). La Argentina que no fue (Tomo I). Las fragilidades de la Argentina agroexportadora (1918-1930). Buenos Aires: IDES.

Lucchini, M., Blanco, T. y Cerra, Á. (2000). El pensamiento industrialista argentino en el período de entreguerras-el estudio de un caso: La influencia de List en Bunge. Estudios Interdisciplinarios de América Latina y el Caribe, 11(2).

Marx, K. ([1867] 2000). El Capital. Crítica de la economía política. México: Siglo XXI. Mokyr, J. (1987). La revolución industrial y la nueva historia económica (I). Revista de Historia Económica / Journal of Iberian and Latin American Economic History (Second Series), 5(02), pp. 203-241.

Murmis, M. y Portantiero, J. C. (1987). Estudios sobre los orígenes del peronismo. Buenos Aires: Siglo XXI.

Nahón, C., Rodriguez, K. y Schorr, M. (2006). El pensamiento latinoamericano en el campo del desarrollo del subdesarrollo: trayectoria, rupturas y continuidades. En CLACSO, Crítica y teoría en el pensamiento social latinoamericano (pp. $327-$ 388). Buenos Aires: CLACSO.

Neffa, J. C. (1998). Modos de regulación, regímenes de acumulación y sus crisis en Argentina (1880-1996): una contribución a su estudio desde la teoría de la regulación. Buenos Aires: Asociación Trabajo y Sociedad - Eudeba - Piette - CONICET.

Notcheff, H. (1994). Los senderos perdidos del desarrollo. Buenos Aires: Elite económica. 
Reche. La Industrialización por Sustitución de Importaciones (ISI): usos y sentidos de una expresión polisémica

Odisio, J. (2014). Lo que vendrá: Las “Tres cartas” de Emilio de Alvear y el presagio de los debates proteccionistas de 1875 y 1876. Ciclos en la historia, la economía y la sociedad, 22(43), pp. 125-145.

Peña, M.(1986). Industrialización y clases sociales en laArgentina. Buenos Aires: Hyspamérica. Peralta Ramos, M. (2007). La economía política argentina: poder y clases sociales (1930-2006). Buenos Aires: Fondo de Cultura Económica.

Pérez Caldentey, E., Sunkel, O. y Torres Olivos, M. (2000). Raul Prebisch (1901-1986). Un recorrido por las etapas de su pensamiento sobre el desarrollo económico. S.1.: Naciones Unidas - CEPAL.

Prebisch, R. ([1949] 1986). El desarrollo económico de la América Latina y algunos de sus principales problemas. Desarrollo Económico, 26(103), 479-502. Recuperado de http://www.jstor.org/stable/3466824.

Prebisch, R. (1987). Cinco etapas de mi pensamiento sobre el desarrollo. Comercio Exterior, 37(5), 345-352.

Rodríguez, O. (1980). La teoría del subdesarrollo de la CEPAL. México: Siglo XXI.

Rostow, W. W. (Ed.). (1967). La economía del despegue hacia el crecimiento autosostenido. Madrid: Alianza.

Rougier, M.y Odisio, J. (2019). El 'canto de cisne' de la industrialización argentina. Desempeño y alternativas en la etapa final de la ISI. Revista de Estudios Sociales, (68), pp. 51-67.

Rougier, M., y Schorr, M. (2012). La industria en los cuatro peronismos: estrategias, politicas y resultados. Buenos Aires: Capital Intelectual.

Sábato, J. (1988). La clase dominante en la Argentina moderna. Formación y características. Buenos Aires: Cisea.

Sartelli, E. y Kabat, M. (2016). Argentine industrialization: A critique of the liberal and dependentist schools. Analytical gains of geopolitical economy (pp. 227-254). Emerald Group Publishing Limited.

Schvarzer, J. (1996). La industria que supimos conseguir. Buenos Aires: Planeta.

Singer, H. W. (1950). Comercio e inversión en países poco desarrollados: distribución de las ganancias entre los países inversores y los deudores. El Trimestre Económico, 17(66(2)), pp. 232-251.

Sunkel, O. (2000). La labor de la CEPAL en sus primeros dos decenios. En CEPAL, La CEPAL en sus 50 años. Notas de un seminario conmemorativo (pp. 33-40). Santiago de Chile: CEPAL.

Sunkel, O. (2011). Reflexiones sobre la vida y obra de Raúl Prebisch. En CEPAL. Homenaje a Raúl Prebisch (1901-1986) (pp. 27-41). Santiago de Chile: CEPAL.

Sweezy, P. M. (1973). Una diferencia crucial entre capitalismo y socialismo. En D. Horowitz, Marx y la economía moderna: cien años de teoría económica marxista. Barcelona: Laia.

Takahashi, H. K. (1986). Del feudalismo al capitalismo. Problemas de la transición. Barcelona: Crítica.

Toynbee, A. (1884). Lectures on the Industrial Revolution in England. Popular Addresses, notes and other fragments. London: Rivingtons. 
Vidal, G. y Guillén, R. (Coords.). (2008). Repensar la teoría del desarrollo en un contexto de globalización: homenaje a Celso Furtado. Buenos Aires: CLACSO.

Villanueva, J. (1972). El origen de la industrialización argentina. Desarrollo Económico, 12(47), pp. 451-476.

Wallerstein, I. (1998). La segunda era de gran expansión de la economía-mundo capitalista (Vol. 3), 1730-1850. Buenos Aires: Siglo XXI. 